\title{
The design of the sampling parameters for CMM of free-form surfaces
}

\author{
Yikun Zhang, Yueping Chen*, and Kaiqi Huang \\ School of Mechanical and Transportation Engineering, Guangxi University of Science and \\ Technology, Guangxi Liuzhou, China
}

\begin{abstract}
In order to improve the inspection accuracy of free-form surface by CMM, this paper adopted the different sampling parameters to research the influence of the measurement accuracy of free-form surface. Through the combination of area uniform block random sampling and Latin hypercube random sampling, the minimum sampling grid block area and ball diameter were taken as the research parameters. Firstly, this research analysed theoretically the influence of measurement accuracy of free-form surface by different sampling parameters. Secondly, carrying out experiments verified the analytical results. Then, the influence of two groups of sampling parameters on the normal deviation of free-form surface could be acquired by analysing the experimental data. Finally, this research could obtain the result of normal deviation of free-form surface. The research results showed that the minimum block area of sampling and the diameter of measuring ball become smaller, and the profile error become larger when the number of measuring points were the same, the more it can reflect the actual contour of the free-form surface, which proves that the measurement accuracy is higher.
\end{abstract}

Keywords: Free-form surface, CMM, Sampling parameters, Latin hypercube sampling.

\section{Introduction}

With the development of modern high-precision manufacturing industry, many researchers and scholars form home and abroad have put forward higher requirements for the research of free-form surfaces. The free-form surfaces are complex surfaces with different shapes/sizes along the three axes of XYZ and without translational symmetry and rotation. The current free shape is widely applied in automotive, aerospace, mold manufacturing, plastic and so on [1]. In order to fully cooperate with the development of various parts and components in related industries in our country and accurately realizing the inspection of complex surfaces parts, the calculation accuracy and work efficiency of complex surfaces have gradually become a major task of the national quality supervision and administration department. In the three-dimensional inspection, the three-dimensional

\footnotetext{
*Corresponding author: chenyueping99@126.com
} 
coordinate measuring machine (CMM) has widely used in various high-precision and complex surface measurement by its superiority of high measurement accuracy and strong adaptability[2].

CMM mainly uses the trigger ball and the scanning ball when inspecting the parts. The way of sampling and acquiring of the discrete data is by measuring a series of discrete points and those measured points are the measurement results [3]. However, the measurement error exists in all kinds of precision measuring mechanics. Meanwhile, the measurement error has a great influence on the measurement accuracy of CMM. The measurement accuracy of CMM is related to the environment, inspection methods, sampling parameters and so on. Chen [3] took two sampling parameters of sampling interval and ball diameter as the research object, and its research showed that the smaller the sampling interval and the smaller the ball diameter, the higher the measurement accuracy. Cao [4] studied the influence of different types of sampling points and effective sampling points of the coordinate measuring machine on the measurement error. Qu [5] proposed a strategy for the distribution of sampling points in the sobol sequence, selecting the effective number of sampling points and optimizing the distribution characteristics of the sampling points. Ainsworth I [6] believed that the error of surface measurement in three-coordinates was related to the measurement area, grid size and ball diameter. Thus, this paper proposed a block Latin hypercube sampling method to analyze the impact of sampling grid area and ball diameter on the accuracy of CMM inspection.

\section{Selection of sampling parameters}

Sampling parameters mainly include measuring ball diameter, sampling grid area, sampling interval, number of sampling points. It will also be affected by the specific conditions of the device under test, system accuracy, and environmental requirements. Thus, this paper focuses on the impact of sampling grid area and ball diameter on the results of CMM.

\subsection{Selection of sampling grid area}

The sampling grid area refers to dividing the area of the test piece into grids. In general, it uses uniform sampling method. The authorS proposed that adopting the block Latin hypercube random sampling acquired sampling points. From a statistical point of view, the partition random sampling method divides randomly the population into several parts, and then selects randomly several parts from each part to form sample. In general, the regional sampling is more accurate than simple random sampling. The partition random sampling can be regarded as uniform area block random sampling when the overall area is randomly selected into small blocks of the same area. According to the sampling principle, the smaller the sampling grid area is and the more uniform the sampling point is. Thus, it can give priority to the smaller sampling grid area.

\subsubsection{Latin Hypercube sampling (LHS)}

In order to better achieve the effect of uniform random distribution in the grid, applying the Latin hypercube can solve the advantage of simple random sampling. The sampling point set is generated by based on the block stochastic method of uniform area and the method of random measuring points of Latin Hypercube theory. The basic principle of Latin hypercube sampling is that the coordinate interval of each dimension in the n-dimensional space $\left[\boldsymbol{x}_{\mathrm{k}}^{\min }, \boldsymbol{x}_{k}^{\max }\right], \mathrm{i} \in[1, \mathrm{n}]$ is uniformly divided into $\mathrm{m}$ intervals. Each interval is 
recorded as $\left[x_{k}^{i-1}, x_{k}^{i}\right], \mathrm{i} \in[1, \mathrm{~m}]$ to ensure that each level of each factor were once studied. It is necessary to draw a sample point in each interval, namely sample $\mathrm{m}^{*} \mathrm{n}$ groups of sample points ${ }^{[8]}$.

\subsection{Selection of ball diameter}

The diameter of the measuring ball is one of the biggest influence factors of sampling parameters. The diameter of the measuring ball is mostly $(0.5 \sim 10) \mathrm{mm}$. It can be concluded that the smaller the ball is, the closer it is to the real position of the contour. Thus, this experiment should select the measuring ball with a smaller diameter as much as. The experiment was selected three measuring balls, including $1.5 \mathrm{~mm}, 5 \mathrm{~mm}, 8 \mathrm{~mm}$ to measure the free surfaces. Finally, it can analyz and conclude the experimental results.

\section{Experimental study}

In order to study the influence of sampling parameters for the inspection error of CMM, this paper adopted the orthogonal experimental method to measure a component. The freeform surface part is as the experimental object and the CAD drawing of the surface is shown in Figure 1. The physical drawing is shown in Figure 2. Applying three coordinate measuring machine from Hexagon Leitz Reference HP (PC-DMIS software, $\mathrm{MPEE}=0.9+\mathrm{L} / 400 \mu \mathrm{m})$ to carry out the experimental research. Its measurement method is the touch-trigger ball, including measuring ball diameter of $1.5 \mathrm{~mm}, 5 \mathrm{~mm}$, and $8 \mathrm{~mm}$. And The number of measuring points is 100 . The specific experimental plan is shown in Table 1 .

Table 1. Orthogonal experiment table.

\begin{tabular}{|l|c|c|l|}
\hline $\begin{array}{l}\text { Experiment } \\
\text { number }\end{array}$ & $\begin{array}{l}\text { Measuring ball } \\
\text { diameter(mm) }\end{array}$ & $\begin{array}{l}\text { grid area S } \\
\left(\mathbf{m m}^{2}\right)\end{array}$ & $\begin{array}{l}\text { the way of taking } \\
\text { points }\end{array}$ \\
\hline L1 & 1.5 & $16^{*} 16$ & Blocked LHS \\
\hline L2 & 1.5 & $20^{*} 20$ & Blocked LHS \\
\hline L3 & 1.5 & $40^{*} 40$ & Blocked LHS \\
\hline L4 & 5 & $16^{*} 16$ & Blocked LHS \\
\hline L5 & 5 & $20^{*} 20$ & Blocked LHS \\
\hline L6 & 5 & $40^{*} 40$ & Blocked LHS \\
\hline L7 & 8 & $16^{*} 16$ & Blocked LHS \\
\hline L8 & 8 & $20^{*} 20$ & Blocked LHS \\
\hline L9 & 8 & $40^{*} 40$ & Blocked LHS \\
\hline L10 & 1.5 & all & Take points evenly \\
\hline L11 & 5 & all & Take points evenly \\
\hline L12 & 8 & all & Take points evenly \\
\hline
\end{tabular}

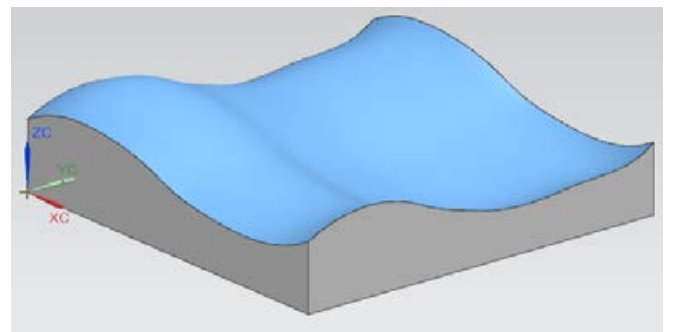

Fig. 1. CAD model of Free-form surface. 


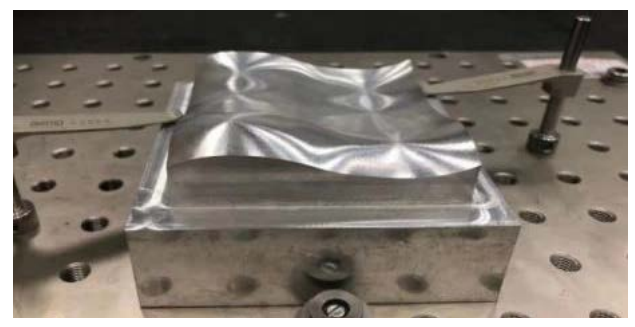

Fig. 2. Workpiece with Free-form surface.

\subsection{Analysis and processing of test data}

It is necessary to process for the measurement data when the free-form surface inspection is completed. The error relationship between the theoretical data and the inspection data can be acquired. and the theoretical and actual coordinate values in the $\mathrm{X}, \mathrm{Y}$, and $\mathrm{Z}$ directions, the deviation in the $\mathrm{X}, \mathrm{Y}$, and $\mathrm{Z}$ directions and the deviation $\mathrm{X}$ in the normal direction can be automatically obtained. The data processing of this measurement mainly includes average value is $\bar{X}$, variance value is $\sigma$, maximum value is $X_{\max }$, minimum value is $X_{\text {min }}$, maximum height of contour error is $H_{\max }$ and profile error is $\mathrm{E}(\mathrm{V})$.

\subsection{The influence of sampling grid area}

Using block Latin hypercube sampling method, selecting the same trigger ball diameter and the same number of measuring points verified the influence of the sampling grid area for the sampling accuracy of the CMM. The schematic diagram of the sampled CAD model is shown in Figure 3. In the orthogonal experiment, adopting three group of experiments were used for control, including L1, L2, L3 and L4, L5, L6 and L7, L8, L9. It can acquire the influence influence of the sampling grid area for the sampling accuracy of the CMM.

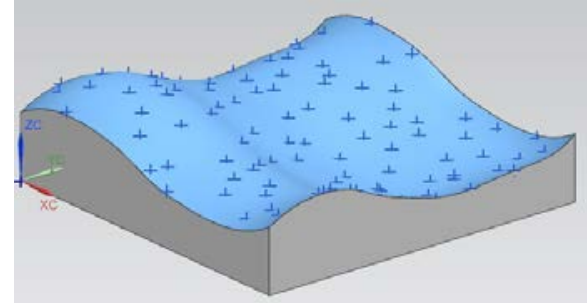

Fig. 3. Surface CAD model and inspection point schematic.

Table 2. Normal error of different sampling grid areas.

\begin{tabular}{|c|c|c|c|c|c|c|c|}
\hline $\begin{array}{c}\text { Number of } \\
\text { measuring } \\
\text { points }\end{array}$ & $\begin{array}{c}\text { Diameter of } \\
\text { the } \\
\text { measuring } \\
\text { ball d }(\mathrm{mm})\end{array}$ & $\begin{array}{c}\text { Sampling } \\
\text { grid } \\
\text { minimum } \\
\text { area } \\
\mathrm{s}\left(\mathrm{mm}^{2}\right)\end{array}$ & $\begin{array}{c}\text { standard } \\
\text { deviation } \\
(\mathrm{mm})\end{array}$ & $\begin{array}{c}\text { Average } \\
\text { value } \\
(\mathrm{mm})\end{array}$ & $\begin{array}{c}\text { Max } \\
(\mathrm{mm})\end{array}$ & $\begin{array}{c}\text { Min } \\
(\mathrm{mm})\end{array}$ & $\begin{array}{c}\mathrm{E}(\mathrm{V}) \\
(\mathrm{mm})\end{array}$ \\
\hline 100 & 1.5 & $16^{*} 16$ & 0.01147 & -0.0196 & 0.00575 & -0.04613 & 0.05188 \\
\hline 100 & 1.5 & $20 * 20$ & 0.01185 & -0.0187 & 0.00519 & -0.0451 & 0.05029 \\
\hline 100 & 1.5 & $40 * 40$ & 0.01188 & -0.0198 & 0.00566 & -0.04167 & 0.04733 \\
\hline
\end{tabular}

The data processing extracted L1, L2 and L3 data as experimental group. The minimum area of the three sets of sampling grids were $16 * 16 \mathrm{~mm}^{2}, 20 * 20 \mathrm{~mm}^{2}$, and $40 * 40 \mathrm{~mm}^{2}$ when the number of measurement points was 100 , the diameter was $1.5 \mathrm{~mm}$ as shown in 
Table 2. It can be seen from Table 3 that the sampling grid area was smaller, the average, maximum, and maximum contour heights were larger to make the contours and measurement accuracy to become more accuracy. And the smaller the standard deviation was, the more stable the measurement data was. Therefore, the experiment should choose the smallest sampling grid area on the surface as much as possible.

\subsection{The influence of the diameter of the ball and the Latin hypercube sampling of the block grid}

The data processing extracted L1, L4 and L7 data as control group. the sampling grid area was $16 * 16 \mathrm{~mm}^{2}$ when the number of measuring points was 100 . and the diameters of the three different measuring balls are $1.5 \mathrm{~mm}, 5 \mathrm{~mm}$ and $8 \mathrm{~mm}$, Contrast with L11, uniform sampling, the number of measuring points is 100 , the diameter of the measuring ball is 5 $\mathrm{mm}$, and the results are analyzed, and the comparison results of the normal deviation of the three ball head diameters and uniform sampling are obtained, as shown in Table 3.

Table 3. Normal Deviation in different Diameter.

\begin{tabular}{|c|c|c|c|c|c|c|c|}
\hline $\begin{array}{c}\text { Number } \\
\text { of } \\
\text { measuring } \\
\text { points }\end{array}$ & $\begin{array}{c}\text { Diameter } \\
\text { of the } \\
\text { measuring } \\
\text { ball d } \\
(\mathrm{mm})\end{array}$ & $\begin{array}{c}\text { Sampling } \\
\text { grid } \\
\text { minimum } \\
\text { area s } \\
\left(\mathrm{mm}^{2}\right)\end{array}$ & $\begin{array}{c}\text { standard } \\
\text { deviation } \\
(\mathrm{mm})\end{array}$ & $\begin{array}{c}\text { Average } \\
\text { value } \\
(\mathrm{mm})\end{array}$ & $\begin{array}{c}\text { Max } \\
(\mathrm{mm})\end{array}$ & $\begin{array}{c}\text { Min } \\
(\mathrm{mm})\end{array}$ & $\begin{array}{c}\mathrm{E}(\mathrm{V}) \\
(\mathrm{mm})\end{array}$ \\
\hline 100 & 1.5 & $16^{*} 16$ & 0.01147 & -0.0198 & 0.00575 & -0.04613 & 0.05188 \\
\hline 100 & 5 & $20^{*} 20$ & 0.0117 & -0.0198 & 0.00433 & -0.0451 & 0.05029 \\
\hline 100 & 8 & $40^{*} 40$ & 0.0116 & -0.0191 & 0.00284 & -0.04753 & 0.05037 \\
\hline 100 & 5 & $\begin{array}{c}\text { Take points } \\
\text { evenly }\end{array}$ & 0.1214 & -0.01848 & 0.00525 & 0.04106 & 0.04631 \\
\hline
\end{tabular}

It can be seen from Table. 3 that the true profile of the curved surface can be reflected when the diameter of the measuring ball is smaller, the maximum profile height is larger. It is $0.00151 \mathrm{~mm}$ larger than the maximum height of the profile when the diameter of the measuring ball is $8 \mathrm{~mm}$. When the diameter is $1.5 \mathrm{~mm}$, the average, maximum, and minimum deviations of the surface normal are the largest. Therefore, the smaller the diameter, the greater the error of the surface profile and the more accurate the measurement results of CMM.

When sampling using the same sampling parameters, the authors compare the maximum height of the contour of the two sampling methods using uniform sampling and block grid sampling. It is found that under the same conditions in the experiment, the block Latin hypercube sampling is higher than the uniform sampling, and the maximum height of the contour is higher, indicating that the inspection accuracy is higher.

\subsection{The influence of the combination of two parameters: the diameter of the measuring ball and the area of the sampling grid}

In order to verify the influence of the combination of the diameter of the measuring ball and the area of the sampling grid on the coordinate measuring machine, Contrast experimental plan L1, that is, when the diameter of the measuring ball is $1.5 \mathrm{~mm}$, the number of measuring points is 100 , and the minimum area of the sampling grid $\mathrm{s}$ is $16^{*} 16$ $\mathrm{mm}^{2}$,Compared with experimental plan L9, when the diameter of the measuring ball is 8 $\mathrm{mm}$, the number of measuring points is 100 , and the minimum area of the sampling grid $\mathrm{s}$ is $40 * 40 \mathrm{~mm}^{2}$, The experimental results are shown in Table 4. The experiment shows that under the same two conditions, the smaller the two sampling parameters, the diameter of 
the measuring ball and the area of the sampling grid, the larger the maximum height of the profile, and the closer to the actual curved surface, the more accurate the measurement result is.

Table 4. Normal deviation of surface.

\begin{tabular}{|c|c|c|c|c|c|c|c|}
\hline $\begin{array}{c}\text { Number of } \\
\text { measuring } \\
\text { points }\end{array}$ & $\begin{array}{c}\text { Diameter } \\
\text { of the } \\
\text { measuring } \\
\text { ball d(mm) }\end{array}$ & $\begin{array}{c}\text { Sampling } \\
\text { grid } \\
\text { minimum } \\
\text { area s } \\
\left(\mathrm{mm}^{2}\right)\end{array}$ & $\begin{array}{c}\text { standard } \\
\text { deviation } \\
(\mathrm{mm})\end{array}$ & $\begin{array}{c}\text { Average } \\
\text { value } \\
(\mathrm{mm})\end{array}$ & $\begin{array}{c}\text { Max } \\
(\mathrm{mm})\end{array}$ & $\begin{array}{c}\text { Min } \\
(\mathrm{mm})\end{array}$ & $\begin{array}{c}\mathrm{E}(\mathrm{V}) \\
(\mathrm{mm})\end{array}$ \\
\hline 100 & 1.5 & $16^{*} 16$ & 0.01147 & -0.0198 & 0.00575 & -0.04613 & 0.05188 \\
\hline 100 & 8 & $40^{*} 40$ & 0.01205 & -0.0189 & 0.00401 & -0.04326 & 0.04727 \\
\hline
\end{tabular}

\section{Conclusions}

For the problem of sampling parameters for three-coordinate measurement of free-form surfaces, this paper mainly studied the influence of different sampling grid areas and ball diameters for the normal deviation of the surface. And author applying Latin in hypercube random sampling in uniform area block random sampling compared with the uniform measuring point method. It was found that the smaller the sampling grid area and the larger the profile, it can reflect the true surface accuracy when the number of measuring points is the same. The higher the sampling accuracy, it was easier to detect the trough of the curved surface profile when the number of measuring points was the same. Thus, the accuracy of the measurement can be improved.

This work was financially supported by the National Nature Science Foundation of China (51565006,51765007), the Natural Science Foundation of Guangxi Province (2016GXNSFAA380111,2018GXNSFAA050085),Project supported by Guangxi University high level innovation team and outstanding scholar program in 2016 ([2016] No.42), Project supported by innovation team support program of Guangxi University of science and technology ([2017]64).

\section{References}

1. Mali R A, Gupta T, Ramkumar J . A comprehensive review of free-form surface milling- Advances over a decade[J]. Journal of Manufacturing Processes, 2021, 62:132-167.

2. Editorial Department of China Highway Journal of Highway and Transport, Review of China's Automotive engineering Research Progress:2017,30(06):1-197. (in Chinese)

3. Dawei Chen, Yueping Chen, Yi Yang, Xiaohui Zhou. Sampling Parameter Selection of CMM for Complex Surface [J]. Machinery Design \& Manufacture,2018(01):209-211.

4. $\mathrm{Xu}$ Cao, Ming Li, Qingyue Wei, Wei Li. Research on the Influence of Measuring Points on Precision in CMM [J]. Machinery Manufacturing,2013,51(04):71-74.

5. Li-gang QU, Hong-xia LIU, Ming LI, Lin-dong ZHANG. Research and application of sampling point distribution strategy based on Sobol sequence[J]. Forging \& Stamping Equipment \& Manufacturing Technology,2019,54(06):101-105.

6. Ainsworth I, Ristic M, Brujic D. CAD-Based Measurement Path Planning for FreeForm Shapes Using Contact Probes[J]. International Journal of Advanced Manufacturing Technology, 2000, 16(1):23-31. 